\title{
Potencial de aproveitamento de água pluvial para fins não potáveis na Universidade
}

\section{do Estado do Pará}

\author{
Potential for the use of pluvial water for potable purposes in the University of the State of Pará \\ Potencial para el uso de agua pluvial para fines potable en la Universidad del Estado de Pará
}

Recebido: 14/04/2021 | Revisado: 20/04/2021 | Aceito: 27/04/2021 | Publicado: 11/05/2021

Bruna Tayná Pereira Castro

ORCID: https://orcid.org/0000-0003-1044-4396 Universidade do Estado do Pará, Brasil

E-mail: brunacastroeng@gmail.com

Caroline Brasil de Souza

ORCID: https://orcid.org/0000-0001-5168-9723 Universidade do Estado do Pará, Brasil

E-mail: carolbrasileng@gmail.com

Eduarda Costa Ferreira

ORCID: https://orcid.org/0000-0001-9094-1151 Universidade do Estado do Pará, Brasil

E-mail: eduardacostaferreira5@gmail.com

Glauber Epifanio Loureiro

ORCID: https://orcid.org/0000-0002-0801-5296 Universidade do Estado do Pará, Brasil E-mail: epfanio@uepa.br

\begin{abstract}
Resumo
A captação de água pluvial é uma maneira viável de otimizar o uso dos recursos hídricos e estimular o desenvolvimento sustentável. O objetivo deste artigo é determinar o potencial de economia de água no Bloco I da Universidade do Estado do Pará (UEPA). Para isso, o estudo foi realizado com a aplicação do Netuno, um software computacional para análise da água de chuva que concede o potencial de economia de água para fins menos nobres para cada volume de reservatório. Dados diários de precipitação num período de 31 anos (1987-2017) foram considerados, bem como área de captação de $543,55 \mathrm{~m}^{2}$, número de usuários e demandas de água para fins não nobres e pluviais. A demanda de água total foi de 30L/estudante.dia; as demandas de água de chuva foram tomadas como uma porcentagem da demanda de água para fins menos nobres, considerou-se $40 \%$ e $100 \%$. Os resultados indicaram potenciais de economia de água para fins menos nobres de $23,21 \%$ e $33,19 \%$, e volumes de reservatórios ideais de 19.250L e 18.750L. A Universidade do Estado do Pará-Marabá/PA possui potencial favorável de aproveitamento de água de chuva como forma de economia da água fornecida pelo sistema de abastecimento da Universidade, devido aos altos índices pluviométricos e grandes áreas de captação, entretanto, o dimensionamento do tanque de armazenamento de água pluvial deve ser realizado de acordo para cada situação específica, de forma a avaliar a viabilidade do projeto.
\end{abstract}

Palavras-chave: Armazenamento de água pluvial; Captação de água pluvial; Volumes de reservatórios ideais.

\begin{abstract}
Rainwater harvesting is a viable way to optimize the use of water resources and encourage sustainable development. The purpose of this article is to determine the water saving potential in Block I of the University of the State of Pará (UEPA). For this, the study was carried out with the application of Neptune, a computer software for the analysis of rainwater that grants the potential of saving water for less noble purposes for each volume of reservoir. Daily rainfall data over a period of 31 years (1987-2017) were considered, as well as a catchment area of $543.55 \mathrm{~m}^{2}$, number of users and water demands for non-noble and rainy purposes. The total water demand was $30 \mathrm{~L} /$ student.day; rainwater demands were taken as a percentage of water demand for less noble purposes, $40 \%$ and $100 \%$ were considered. The results indicated water saving potentials for less noble purposes of $23.21 \%$ and $33.19 \%$, and ideal reservoir volumes of 19,250L and 18,750L. The State University of Pará-Marabá / PA has a favorable potential for using rainwater as a way of saving water supplied by the University's supply system, due to the high rainfall and large catchment areas, however, the dimensioning of the tank rainwater storage must be carried out in accordance with each specific situation, in order to assess the feasibility of the project.
\end{abstract}

Keywords: Harvesting rainwater; Ideal reservoir volumes; Stormwater storage. 


\section{Resumen}

La captación de agua de lluvia es una forma viable de optimizar el uso de los recursos hídricos y fomentar el desarrollo sostenible. El objetivo de este artículo es determinar el potencial de ahorro de agua en el Bloque I de la Universidad del Estado de Pará (UEPA). Para ello, el estudio se realizó con la aplicación de Neptune, un software informático para el análisis de aguas pluviales que otorga el potencial de ahorro de agua para fines menos nobles por cada volumen de embalse. Se consideraron los datos de precipitación diaria durante un período de 31 años (19872017), así como un área de captación de $543,55 \mathrm{~m}^{2}$, número de usuarios y demandas de agua para fines no nobles y lluviosos. La demanda total de agua fue de 30L / alumno.día; Las demandas de agua de lluvia se tomaron como porcentaje de la demanda de agua para fines menos nobles, se consideraron $40 \%$ y $100 \%$. Los resultados indicaron potenciales de ahorro de agua para propósitos menos nobles de $23.21 \%$ y $33.19 \%$, y volúmenes ideales de reservorio de 19,250L y 18,750L. La Universidad Estatal de Pará-Marabá / PA tiene un potencial favorable para utilizar el agua de lluvia como una forma de ahorro de agua suministrada por el sistema de abastecimiento de la Universidad, debido a la alta precipitación y las grandes áreas de captación, sin embargo, el dimensionamiento del tanque de almacenamiento de agua de lluvia debe ser llevado a cabo de acuerdo con cada situación específica, con el fin de evaluar la viabilidad del proyecto.

Palabras clave: Almacenamiento de agua de lluvia; Recolección de agua de lluvia; Volúmenes de reservorio óptimos.

\section{Introdução}

Sabe-se que a água é um dos recursos naturais mais preciosos, uma vez que é indispensável para a manutenção da vida e para o desenvolvimento das atividades humanas na qual possui inúmeros usos, como por exemplo, o abastecimento humano, irrigação, criação de animais, geração de energia, mineração, fins industriais, navegação, turismo e lazer, entre outros.

No entanto, devido ao acelerado crescimento populacional, uso desordenado do solo, desperdício, a demanda de água aumenta cada vez mais (Lima, Dambros, Antonio, Janzen \& Marchetto, 2011). Ainda sobre isso, um estudo realizado por Lopes e Miranda (2016) constatou um desequilíbrio na oferta e demanda de água tendo em vista que o Brasil detém 12\% dos recursos hídricos mundial, uma vez que a região Norte dispõe de 68,5\% da água doce do país, região Nordeste apenas 3,3\%, Sudeste 6\%, Sul com 6,5\% e a região Centro-Oeste com $15,7 \%$.

Diante deste cenário, são adotadas estratégias e fontes alternativas de racionalização deste recurso, em que se podem destacar os sistemas de aproveitamento de água pluvial como uma possibilidade de abastecimento de água com finalidades não potáveis (Lima, Nunes \& Silva, 2017). No âmbito internacional, o interesse pelo aproveitamento de água pluvial é evidente (Salla, Lopes, Pereira, Neto \& Pinheiro, 2013), em países da Europa como por exemplo na Alemanha tal técnica já era promovida o que fez com o que o país progredisse acerca do assunto. No Brasil, os estudos relacionados à racionalização hídrica cresceram consideravelmente por se tratar de um recurso natural de abundância na maioria das regiões brasileiras (Nascimento, Fernandes \& Yoshino, 2016).

No processo de aproveitamento de água pluvial é possível identificar diversos aspectos positivos como, por exemplo, redução na demanda de água para fins menos nobres e alívio do estresse de água da região auxiliando na redução de enchentes que ocorrem principalmente em grandes cidades. Ademais, vale destacar que o uso de água pluvial é uma das soluções mais simples e de baixo custo por preservar a água além de promover o uso sustentável do recurso de modo a garantir sua quantidade e qualidade para futuras gerações (Yoshino, Fernandes \& Yshihara, 2014). Por este motivo, o aproveitamento de água da chuva vem se tornando cada vez mais relevante como uma alternativa para combater a escassez hídrica e reduzir o consumo de água para fins não potáveis (Rezende \& Tecedor, 2017).

De acordo com ABNT (2007), na NBR 15527 que dispõe sobre o aproveitamento da água da chuva nas coberturas de áreas urbanas para fins não potáveis, a água pluvial coletada é indicada para descarga de bacias sanitárias, irrigação de jardins, limpeza de automóveis e áreas externas, lavagem de roupas, abastecimento de fontes e espelhos d'água e reserva de incêndios. Portanto, o município de Marabá, situado na região Amazônica, apresenta índices pluviométricos elevados, que de acordo com o Banco de Dados Meteorológicos para Ensino e Pesquisa (BDMEP) do Instituto Nacional de Meteorologia (INMET) a cidade 
possui precipitação anual média de $1.841 \mathrm{~mm}$, o que representa um potencial a ser explorado, contudo, percebe-se que o aproveitamento da água pluvial em prédios públicos ainda é incipiente na localidade.

Marinoski, Ghisi e Gómez (2014), afirmam que prédios utilizados para atividades de ensino são exemplos de construções com grande potencial para aproveitamento da água da chuva para fins não potáveis, pois possuem telhados com grande capacidade de captação e a água da chuva captada pode ser utilizada para atividades secundárias tais como para lavar o chão, lavar banheiros, descarga de vasos sanitários e rega de plantas e jardim.

Nesse contexto, a Universidade do Estado do Pará-Marabá/PA torna-se ponto principal dessa discussão ao levar em consideração os índices pluviométricos à mesma representa um possível potencial para reservação de águas pluviais, devido a região que está inserida e por possuir blocos com extensos telhados que se tornam excelentes áreas de captação. Destaca-se ainda que a instituição seja responsável não apenas pela formação de profissionais, mas também no incentivo de práticas sustentáveis para com o meio ambiente, através de propostas, medidas e incentivos para conservação da água, motivando os indivíduos a utilizar o recurso da maneira adequada.

Portanto, a pesquisa fundamenta-se em desenvolver um estudo sobre o aproveitamento de água de chuva para fins não potáveis de forma que desperte o interesse para a utilização desse sistema, bem como a conscientização pelo uso racional da água. Nessa conjuntura, o presente estudo tem por objetivo indicar o potencial de economia de água para fins não potáveis bem como sua reservação para o Bloco I da Universidade do Estado do Pará- Marabá/PA.

\section{Revisão de Literatura}

\subsection{Utilização de água da chuva no mundo}

A captação e aproveitamento de água da chuva não é uma prática nova, visto que essa tecnologia caracteriza-se por ser um processo milenar que já se mostrava ser adotado por civilizações antigas como Astecas, Maias e Inca (Torquato, Moreira \& Bittencourt, 2015). Espelhando-se nisso, alguns estudos relatam que o armazenamento de água pluvial é comumente utilizado como alternativa de suprimento de água tanto em países desenvolvidos como em desenvolvimento ao redor do mundo (Adugna, Jensen, Lemma \& Gebrie 2018).

Na Alemanha e no Japão, por exemplo, a iniciativa de captar água pluvial iniciou-se com o objetivo de retenção das águas das chuvas como medida preventiva de combater enchentes, entretanto esse incentivo fez com que os países desenvolvessem e aprimorassem os seus processos de aproveitamento de água sendo muito utilizados nas residências, edifícios, instituições de ensino, entre outros (Teixeira, Zattoni, Nagalli, Freira \& Teixeira, 2016).

Fewkes (1999), examinou a captação de água de chuva através da instalação de um tanque de $2.032 \mathrm{~L}$ em uma propriedade no Reino Unido e monitorou por um período de doze meses. Os resultados do monitoramento demonstraram uma eficiência de 4\% em junho para 100\% em setembro. Já Zhou, Shao \& Zhang (2015) em estudo de caso na China, desenvolveram um modelo computacional de simulação para avaliar o potencial de armazenamento de água pluvial através das relações da demanda de água, capacidade do reservatório com o escoamento superficial médio anual coletado.

Na França, Vialle, Sablayrolles, Lovera, Huau, \& Montréjaud-vignoles (2011) instalaram um sistema de captação de água pluvial e subsequente uso em descargas de vasos sanitários e monitorou durante o período de um ano. Os resultados do estudo demonstraram que o sistema poderia reduzir significativamente o consumo de água para fins não potáveis, uma vez que o sistema indicou uma eficiência de $87 \%$ de economia de água.

Eroksuz e Rahman (2011) realizaram estudos em três cidades da Austrália: Sydney, Newcastle e Wollongong, e obtiveram economia de água para fins não potáveis entre $21 \%$ e $57 \%$ ao longo do ano, além disso, analisando diferentes tipos de reservatórios para a obtenção de maior economia, concluiu-se que o tamanho do reservatório estava diretamente relacionado à área de captação devido ao fato de que uma área de captação pequena não seria capaz de encher o reservatório de modo tão 
frequente quanto em áreas de captação maior.

\subsection{Aproveitamento de água da chuva no Brasil}

Segundo a Associação Brasileira de captação e manejo de água de chuva- ABCMAC no Brasil há aproximadamente 25 anos, existiam poucas experiências de captação e aproveitamento da água de chuva. O semiárido brasileiro foi o pioneiro em adotar o método de captação de água da chuva, uma vez que fatores como a falta de água nos açudes, lagoas e rios em determinadas épocas do ano e a salinidade das águas subterrâneas levaram a população nordestina a utilizar a água da chuva para suprir as necessidades de uso doméstico e as atividades na agricultura.

De acordo com Galvíncio e Moura (2015) a partir do começo dos anos 90 programas foram criados por organizações não governamentais, organizações de base e comunidades com o intuito de melhorar a qualidade de vida da população do semiárido, como exemplo, pode-se citar o "Programa um Milhão de Cisternas" popularmente conhecido por P1MC, que incentivou a construção de cisternas para o aproveitamento da água da chuva com meta de construir um milhão de cisternas em 11 estados brasileiros inseridos no semiárido.

Atualmente, em algumas metrópoles brasileiras como São Paulo e Rio de Janeiro, já existem leis que têm por objetivo obrigar as construções a reterem a água de chuva visando a diminuição das enchentes urbanas (Cohim, Garcia \& Kiperstok, 2008). Percebe-se que o aproveitamento de água da chuva como fonte alternativa para fins não potáveis vem sendo amplamente utilizado e atualmente com o surgimento de leis que tratam sobre a captação da água da chuva como método de contenção de cheias e abastecimento de água, o número de usuários tende a aumentar.

\subsection{O cenário legislativo para o aproveitamento de água pluvial no Brasil}

Segundo Pacheco, Gómez, Oliveira e Teixeira (2017) o Brasil tem uma precipitação abundante em todo o seu território, entretanto, os resultados obtidos em sua investigação demonstraram que grande parte do território carece de regulamentação que incentive a coleta e uso de água pluvial por meio de sistemas de captação de água da chuva nos níveis federal e municipal. Nesse contexto, crescente preocupação com o meio ambiente e o uso consciente da água, a utilização de água tratada para alguns fins não potáveis tornou-se cada vez mais inviável o que tem impulsionado o aumento de sistemas de captação de água da chuva para fins não potáveis (Tugoz, Bertolini \& Brandalise, 2017).

Destaca-se ainda que não exista uma legislação específica para o aproveitamento de água da chuva em nível federal, cabe a cada estado e município instruírem leis sobre captação de água pluvial. Não obstante, em 1997 foi elaborada a Política Nacional de Recursos Hídricos - PRNH, Lei Federal n 9.433/97 (Brasil, 1997) como a primeira idealização de preservação e racionalização de uso da água.

$\mathrm{Na}$ época, dentre os objetivos desta lei eram assegurar a necessária disponibilidade de água as futuras gerações, incentivar a utilização racional dos recursos hídricos e realizar a prevenção contra eventos hidrológicos críticos de origem natural ou causados por ação antrópica. Recentemente, foi publicada a Lei $\mathrm{n}^{\circ}$ 13.501/2017 que inclui mais um objetivo a PNRH: Incentivar e promover a captação, a preservação e o aproveitamento de águas pluviais (Brasil, 2017).

No entanto, apesar dessa preocupação com os recursos hídricos e o novo incentivo ao aproveitamento de água pluvial, o Brasil ainda necessita de legislações específicas que conduzam às práticas de aproveitamento e estabeleçam casos de obrigatoriedade. Pensando nisso, na carência de uma política nacional em termos de regulamentação da coleta de águas pluviais, algumas leis estaduais e principalmente regulamentos municipais assumiram a tarefa de cobrir essa lacuna legislativa.

A cidade de São Paulo, por exemplo, foi pioneira quando em janeiro de 2002, aprovou a Lei no 13.276 que, tornou obrigatória a execução de reservatórios para armazenar águas de chuva coletadas por coberturas e pavimentos localizados em lotes ou edificações que tenham área impermeabilizada superior a $500 \mathrm{~m}^{2}$ (Brasil, 2002). Já em Curitiba, a Lei no 10.175/2003 
determina que em edificações com mais de $250 \mathrm{~m}^{2}$, conjuntos habitacionais ou construções unifamiliares em série, são obrigatórios a captação e o aproveitamento de águas pluviais (Brasil, 2013).

Diante disso, com a finalidade de buscar diminuir o consumo de água para fins não potáveis e elevar ao máximo o aproveitamento de água da chuva, foram criadas normas técnicas voltadas aos requisitos para instalações do sistema. Nesse sentido, em 1989 a Associação Brasileira de Normas Técnicas - ABNT publicou a NBR 10.844 de instalações de águas prediais a qual fixa exigências e critérios necessários aos projetos de instalações de drenagens de águas sendo aplicados em coberturas de edifícios, terraços, pátios, quintais, entre outros (ABNT, 1989).

Em 2007 surge a NBR 15.527 denominada de "Aproveitamento de coberturas em áreas urbanas para fins não potáveis - Requisitos", tendo como principal objetivo fornecer requisitos para o aproveitamento de água de chuva de coberturas em áreas urbanas para fins não potáveis. Além disso, a mesma cita que:

Aplica-se a usos não potáveis em que as águas de chuva podem ser utilizadas após tratamento adequado como, por exemplo, descargas em bacias sanitárias, irrigação de gramados e plantas ornamentais, lavagem de veículos, limpeza de calçadas e ruas, limpeza de pátios, espelhos d'água e usos industriais (ABNT, 2007).

\section{Material e Métodos}

\section{1 Área de estudo}

A realização do levantamento do potencial de captação de água pluvial situa-se no Município de Marabá localizado no Sudeste do Estado do Pará especificamente no campus VIII da Universidade do Estado do Pará, como pode-se observar a Figura 1 abaixo.

Figura 1 - Localização e acesso.

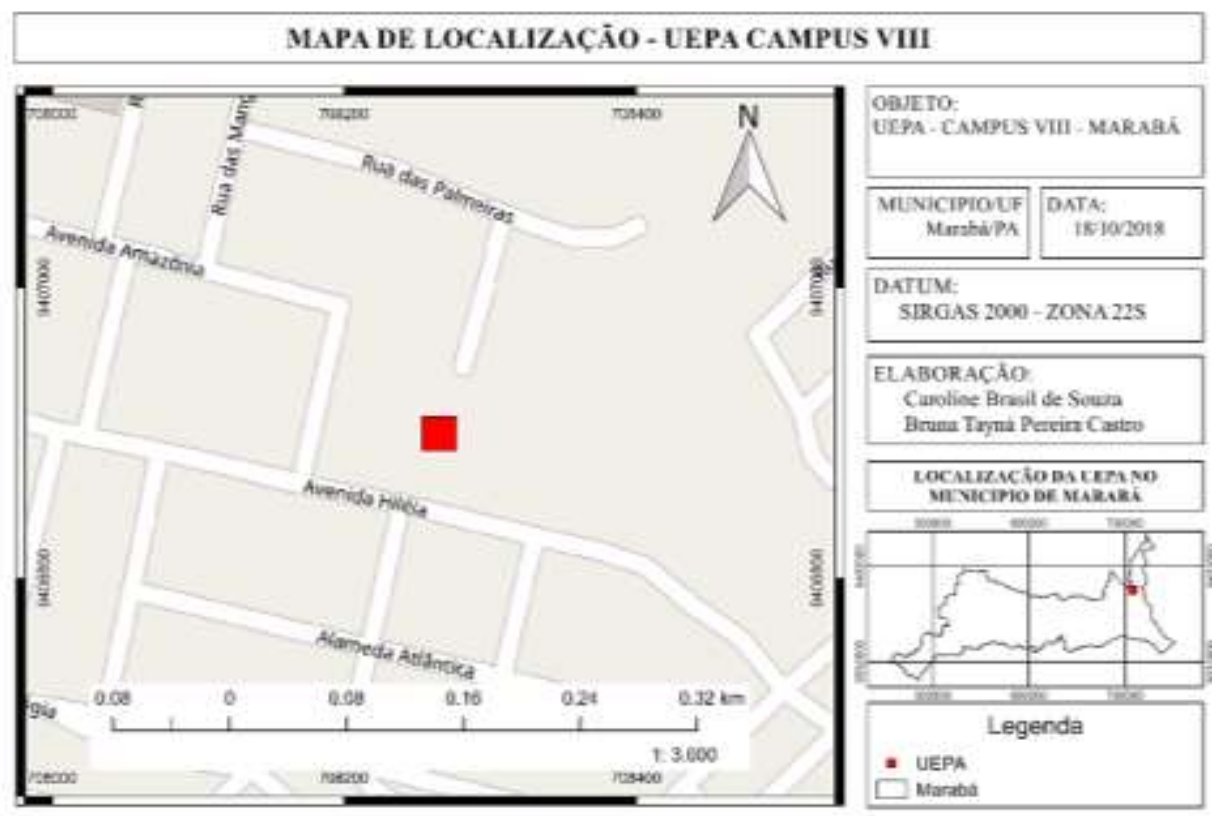

Fonte: Autores (2018).

\subsection{Determinação da área de captação}

Para o correto dimensionamento e determinação do potencial de aproveitamento de água pluvial foi necessário o levantamento da área total do telhado do Bloco I para captação de água que foi determinada a partir das medidas da cobertura do bloco, dado que as dimensões foram obtidas através do auxílio de uma trena de fibra de vidro de $100 \mathrm{~m}$ para posteriormente realizar a medição da área do telhado, como mostra a Figura 2. 
Figura 2 - Cobertura do bloco I da UEPA.

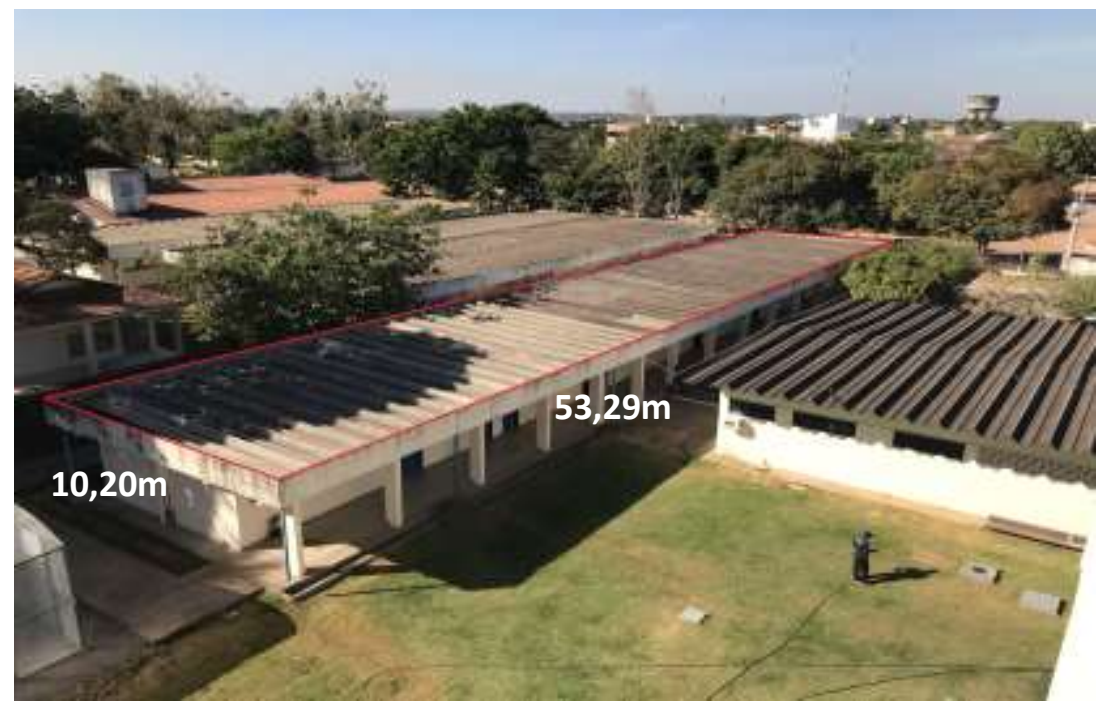

Fonte: Autores (2018).

Para a realização do cálculo da área de cobertura utilizou-se a equação (1) como se pode observar abaixo conforme descrito na Associação Brasileira de Normas Técnicas - ABNT (1989) que pode ser encontrada na NBR 10844:

$$
A=a \times b
$$

Em que:

A corresponde à área total do telhado do bloco $\mathrm{I}\left(\mathrm{m}^{2}\right)$

a representa a largura do telhado $(\mathrm{m})$

b corresponde Comprimento do telhado (m)

\subsection{Dados de Precipitação}

Os dados pluviométricos diários para o período de 01/01/1987 a 31/12/2017 foram levantados através do acesso ao Banco de Dados Meteorológicos para Ensino e Pesquisa - BDMEP disponível no portal do INMET, os quais foram coletados na estação meteorológica 82562 localizada na área urbana do município de Marabá-PA sendo a estação mais próxima do Campus. Tais dados constituem-se em uma série temporal de 31 anos (cerca de 11.285 dias). Os dados climáticos de precipitação foram obtidos por meio de informações disponibilizadas por Alvares et al., (2013) que aborda sobre a classificação de Koppen para o Brasil.

Com base nesses dados de precipitação da cidade, pode-se estimar o volume de água pluvial a serem aproveitados e as seus arranjos durante o ano, além disso, vale ressaltar que o software Netuno considera que os dias em que as medições estavam faltando ou não eram precisas, a precipitação é zero para maior confiabilidade do resultado da simulação já que os dados não devem conter descontinuidades. $\mathrm{O}$ valor adotado para o descarte de precipitação inicial é de $2 \mathrm{~mm}$, conforme recomendado pela NBR 15527 (ABNT, 2007).

\subsection{Coeficiente de escoamento superficial (Runoff)}

Segundo Villarreal e Dixon (2005) os telhados representam grande parte das coberturas impermeáveis e, em geral, os primeiros componentes construtivos a entrar em contato com a água da chuva, logo, oferecendo um grande potencial para seu aproveitamento. Nesse contexto, para efeito de cálculo, o volume de água de chuva que pode ser aproveitado não é o mesmo 
precipitado, para tanto, utiliza-se o coeficiente de escoamento superficial, também denominado coeficiente de runoff que é o quociente entre a água que é escoada superficialmente pelo total da água precipitada (Tomaz, 2009).

Ainda segundo o autor, tais perdas são devidas à limpeza do telhado, evaporação, autolimpeza, entre outros fatores. Vale ressaltar que o coeficiente de runoff é influenciado essencialmente pelo tipo de material utilizado na cobertura. A Tabela 1 a seguir, demonstra os valores de coeficiente.

Tabela 1 - Coeficiente de valores de Runoff.

\begin{tabular}{cc}
\hline Material & Coeficiente de Runoff \\
\hline Telhas cerâmicas & 0,8 a 0,9 \\
Telhas esmaltadas & 0,9 a 0,95 \\
Telhas corrugadas de metal & 0,8 a 0,9 \\
Cimento & 0,8 a 0,9 \\
Plástico & 0,9 a 0,95 \\
\hline
\end{tabular}

Fonte: Tomaz (2009).

O consumo de água no Campus da universidade abrange desde os usos para consumo humano como também para irrigação e utilização nas instalações de água fria. Nesse contexto, a água utilizada para os variados usos é proveniente do abastecimento de reservatório elevado a partir da captação subterrânea.

Nessa conjuntura, vale ressaltar que os setores de aula não possuem monitoramento de consumo de água por hidrômetros, dessa maneira fez-se necessário a utilização de métodos de previsão de consumo mensal de água existente na literatura. Segundo Von Sperling (2014) denomina-se consumo per capita o consumo médio de água por indivíduo e tal demanda de água pelos indivíduos é expressada em L por habitante por dia (L/hab.dia). Em revisões bibliográficas, o mesmo autor determinou valores inerentes ao consumo per capita de água conforme demonstrado na Tabela 2, que podem ser utilizados para quantificar o consumo.

Tabela 2 - Consumo de água.

\begin{tabular}{|c|c|c|}
\hline $\begin{array}{c}\text { Estabelecimento (categoria e } \\
\text { subcategoria) }\end{array}$ & Unidade (unid.) & Faixa de Vazão (L/unid.dia) \\
\hline Escola & \multirow{4}{*}{ Estudante } & \\
\hline $\begin{array}{c}\text { com lanchonete, ginásio, } \\
\text { chuveiros }\end{array}$ & & $50-100$ \\
\hline $\begin{array}{c}\text { com lanchonete, sem ginásio e } \\
\text { chuveiros }\end{array}$ & & $40-80$ \\
\hline $\begin{array}{c}\text { sem lanchonete, ginásio e } \\
\text { chuveiro }\end{array}$ & & $20-60$ \\
\hline
\end{tabular}

Fonte: Von Sperling (2014).

Em uma estimativa geral realizada por Tomaz (2003), o consumo médio de água para escolas e universidades varia de 10 a $50 \mathrm{~L} /$ dia por aluno, e $210 \mathrm{~L} /$ dia por empregado, sendo que este consumo é distribuído em diversos usos variando conforme a tipologia da edificação. Em outro estudo realizado por Kalbusch, Gonçalves, Cureau, Defaveri \& Ramos (2018), o 
consumo médio encontrado para edifícios públicos ao longo de um período de 12 meses foi de 39 L/ usuário. Dia.

Tendo em vista que é necessário o quantitativo de usuários do sistema para que se possa estimar o consumo de água a partir dos dados de população de alunos e docentes matriculados e lotados no Bloco I nos turnos matutino, vespertino e noturno fornecidos pela secretaria da universidade, tais informações puderam ser levantadas, visto que o consumo pode ser entendido como o per capita multiplicado pelo número de usuários. Um ponto relevante observado foi à utilização de água para fins não potáveis em diversas finalidades no Campus, uma vez que tal aspecto analisado mostrou a oportunidade de compensação para que a prática fosse mudada para o uso de água da chuva.

\subsection{Percentagem de água para fins não potáveis a ser substituída por água pluvial}

Em relação à demanda total de água, parte da mesma é destinada para fins potáveis, ou seja, é utilizada para higiene pessoal, para consumo e na preparação de alimentos e outra parcela é utilizada para fins não potáveis, como lavagem de roupas, carros, pisos, calçadas, na irrigação de jardins e na descarga de vasos sanitários (Yoshino, 2012).

Em um estudo realizado por Ghisi e Ferreira (2017), encontrou-se o percentual de substituição de água para usos não potáveis que pode ser substituído por água pluvial por 39,2\%, 40,1\% e 42,7\% respectivamente para três blocos de apartamento totalizando uma média de 40,66\%. Ainda, de acordo com Morais (2017) 38\% do consumo da água para usos não potáveis no Brasil pode ser substituído por águas de chuva. Esse percentual seria suficiente para atender satisfatoriamente às demandas básicas de águas não potáveis dos usuários podendo ser utilizado nas descargas de vasos sanitários, na lavagem de roupas, tanques, irrigação de jardins e lavagem de carros.

Segundo o manual da (ANA/FIESP \& SINDUSCON-SP, 2005), edificações públicas como escolas e universidades, hospitais, terminais de passageiros de aeroportos, entre outros, o uso da água é muito semelhante ao das edificações comerciais, porém o uso dos ambientes sanitários é bem mais significativo, variando de 35 a $50 \%$ do consumo total.

Assim, neste trabalho realizou-se uma comparação entre as demandas de água pluvial de 40\% (parcial) e 100\% (total) da demanda de água para fins não potáveis a ser substituído através de simulações pelo programa Netuno para que se pudesse observar qual volume ideal do reservatório de armazenamento assim como o melhor potencial de aproveitamento de água da chuva.

\subsection{Programa Netuno}

Elaborado pelo Laboratório de Eficiência Energética em Edificações - LABEEE da Universidade Federal de Santa Catarina (UFSC) o programa Netuno tem por objetivo estimar o potencial de economia de água para fins não potáveis de acordo com a capacidade do reservatório a partir do aproveitamento de água pluvial para usos onde a água não precisa ser potável como, por exemplo, descarga de vasos sanitários, limpeza de pisos, irrigação, entre outros (Ghisi \& Cordova, 2014).

Ademais, a metodologia do programa baseia-se no histórico comportamental já conhecido, com isso, os dados de precipitação devem ser fornecidos em uma base diária e as simulações para os volumes ideais dos reservatórios são calculadas conforme esses dados.

O software Netuno 4.0 oferece a possibilidade de inserir uma demanda de água variável, o que permite usar o modelo de curva que prevê um valor de demanda diferente para cada mês do ano, o que torna o resultado mais confiável. Adicionalmente, a simulação mediante este programa permite apresentar de forma gráfica e intuitiva o volume de água de chuva aproveitada em função do volume de reserva total do sistema.

Para a utilização do Netuno os dados de entrada são os seguintes:

(a) precipitação pluviométrica diária;

(b) área de captação; 
(c) coeficiente de escoamento superficial (runoff);

(d) demanda diária de água per capita;

(e) número de moradores;

(f) percentual da demanda total a ser suprida por água pluvial.

Para determinação do volume ideal, serão analisados o intervalo de valores onde são considerados o volume máximo e o intervalo entre volumes, a diferença de percentual e a demanda atendida. Ademais, são simuladas variações desde o volume inicial do reservatório inferior, em intervalos, até obter o volume ideal e para cada variação o programa calcula um novo potencial de economia até promover um aumento menor ou igual a $0,5 \%$ no potencial de economia de água potável sendo o volume anterior escolhido como ideal.

Portanto, é importante realizar um correto dimensionamento do reservatório de armazenamento de água pluvial para evitar gastos desnecessários quando o reservatório é superdimensionado, ou ainda, apresentando uma baixa eficiência quando é subdimensionado (Rupp, Munarim \& Ghisi, 2011). A Figura 3 a seguir, demonstra o fluxograma qualitativo da metodologia utilizada para com a realização do presente estudo.

Figura 3 - Fluxograma representando a metodologia seguida.

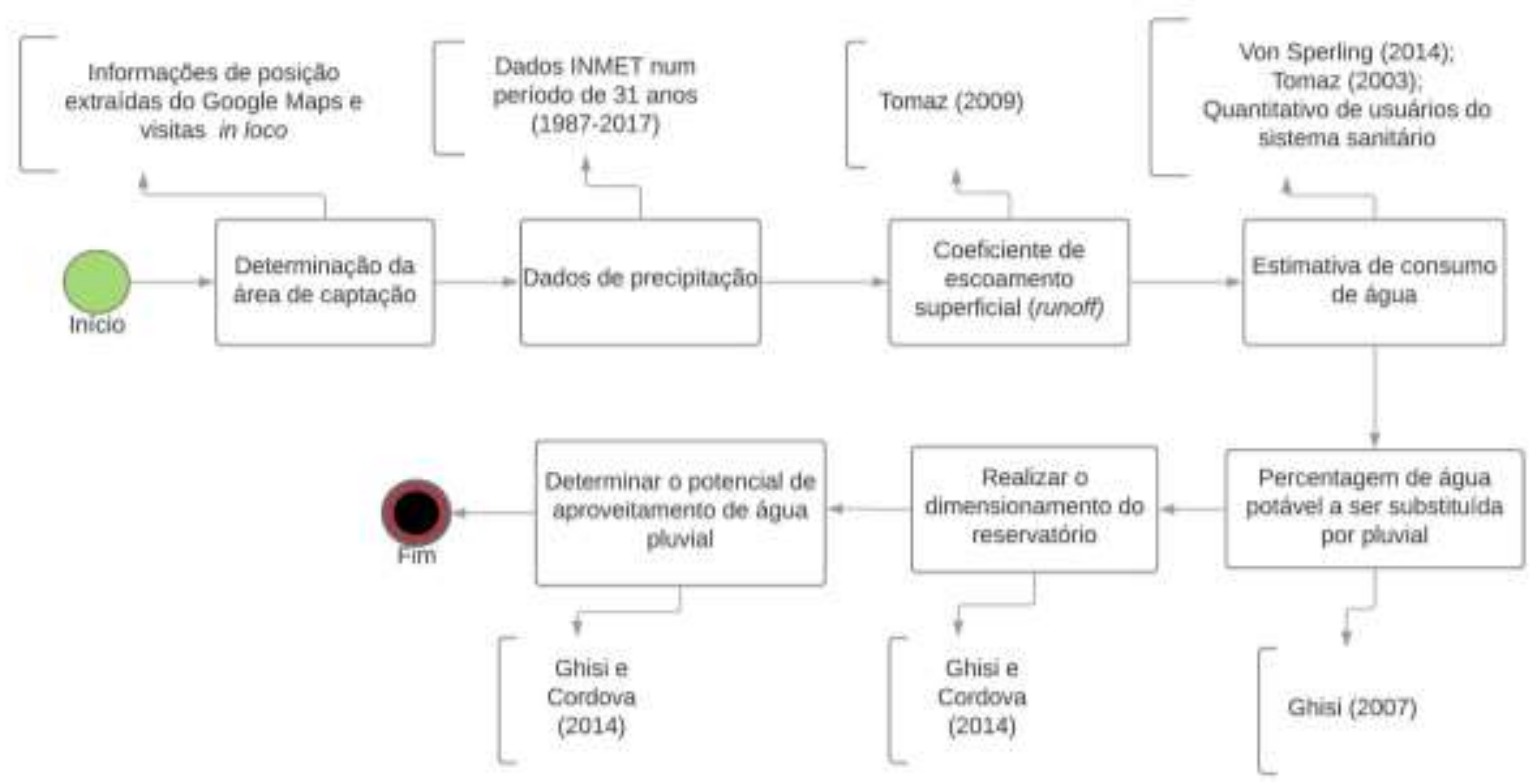

Fonte: Autores (2018).

\section{Resultados e Discussão}

\section{1 Área de captação}

A partir das medições in loco através das visitas técnicas e sendo o cálculo da área de cobertura realizado de acordo com o descrito na norma técnica da ABNT (1989) disposto na NBR 10844, isto é, a área do telhado, o valor encontrado foi de $543,55 \mathrm{~m}^{2}$. Com isso observou-se que as telhas da área de cobertura são constituídas de fibrocimento e calhas impermeáveis que conduzem toda a água do telhado para infiltrar no solo.

Além disso, as telhas possuem uma inclinação (i) igual a $10 \%$ já as calhas apresentam uma inclinação de $1 \%$ e são embutidas. Desta forma, não se fez necessário o dimensionamento de calhas, inicialmente, dado que podem ser usadas as já existentes na captação. Nesse segmento, não foram incluídas como área de captação as áreas do pátio, calçadas e gramado, visto que a qualidade da água pluvial varia conforme o local de captação, sendo considerado somente o telhado, por ser uma área com melhores condições. 


\subsection{Dados pluviométricos}

Segundo Alvares et al., (2013) e de acordo com a classificação climática de Köppen, o município encontra-se na faixa de transição Aw que, é caracterizado por possuir clima tropical com estação seca no inverno. Conforme observado na Figura 4, o período chuvoso é notório de outubro a maio, com volumes de água de chuva captado que variam de 37.430 a 48.960 L, e o mais seco de junho a setembro, com volumes de água de chuva captado que variam de 12.300 a $19.950 \mathrm{~L}$, sendo considerados como meses de escassez onde o índice pluviométrico anual é inferior a $60 \mathrm{~mm}$ e a média mensal de precipitação é de 1841 $\mathrm{mm}$.

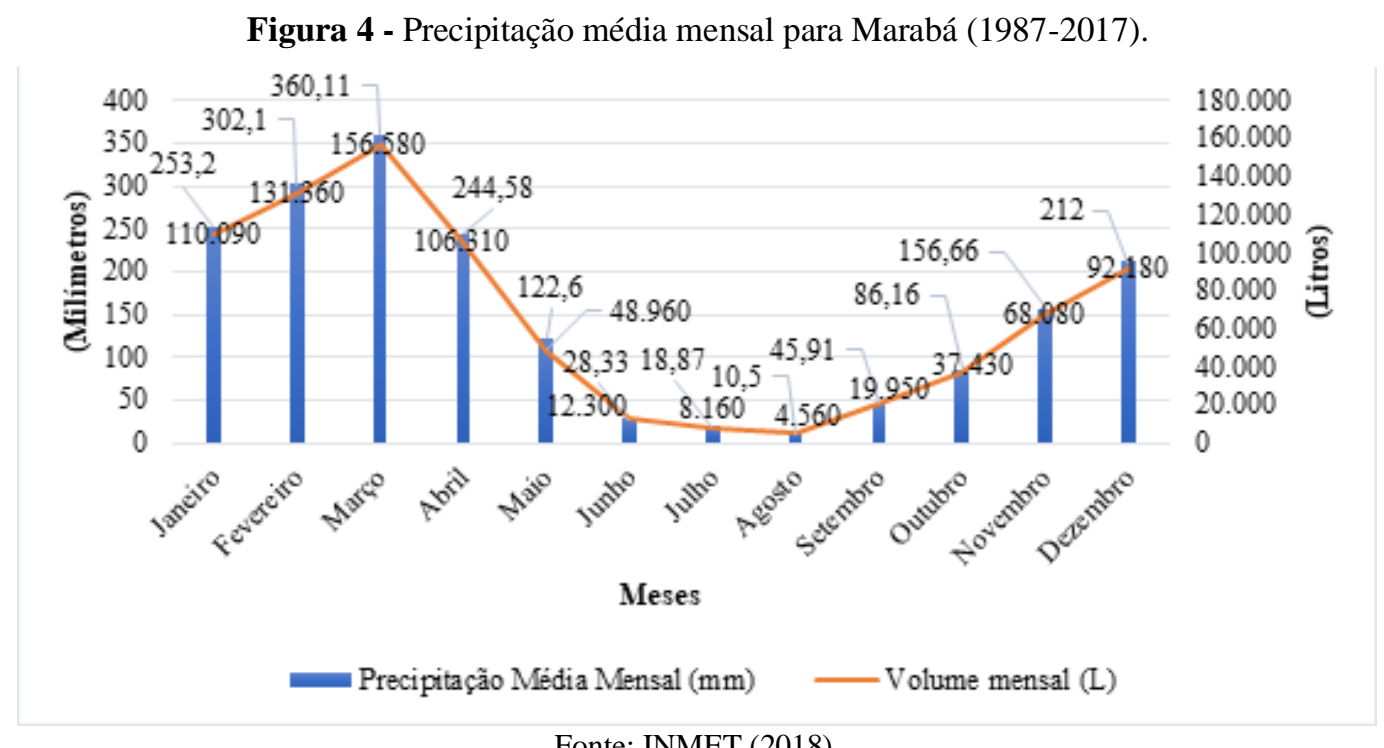

Fonte: INMET (2018).

\subsection{Estimativa do consumo de água}

A partir dos dados fornecidos pela secretaria da universidade foram quantificados 219 usuários entre discentes, docentes e funcionários ativos do Bloco I da UEPA. Ademais, segundo as categorias de Von Sperling (2014), tal setor de aula se adequa na categoria de Escola e na subcategoria "com lanchonete, sem ginásio e chuveiros", no qual o consumo per capita varia entre 40 a $80 \mathrm{~L} / \mathrm{estudante.dia.}$

No entanto, foi adotado o consumo per capita de 30L/estudante. Dia, conforme valor encontrado por Salla et al., (2013) para um bloco de sala de aula da Universidade Federal de Uberlândia em que chegaram ao valor 20 a 30 L/aluno.dia. Com isso, considerando o consumo per capita adotado, calculou-se então a demanda total de água do Bloco I sendo tal valor multiplicado pelo número de alunos, resultando num consumo de água total de $6.570 \mathrm{~L} / \mathrm{dia}$.

\subsection{Simulação de Software Netuno}

Para realização das simulações computacionais foram utilizados dados de entradas, conforme demonstrados na Tabela 3. Nesse sentido, foram calculados o potencial de economia de água para fins não potáveis em função da demanda de água de chuva, número de usuários e área de superfície de captação de 543,55 m². Foi realizado simulações para as demandas de água de chuva de $40 \%$ e $100 \%$ da demanda de água para usos não potáveis a ser substituída, onde foram obtidos os seguintes resultados, conforme ilustrado na Tabela 3 a seguir. 
Tabela 3 - Dados de entrada no programa Netuno.

\begin{tabular}{cc}
\hline Dados de entrada & Bloco I do Campus VIII \\
\hline Área de captação $\left(\mathrm{m}^{2}\right)$ & 543,55 \\
Demanda total de água (L per capita/ dia) & 30 \\
População (pessoas) & 219 \\
Percentual de demanda total a ser substituída por & 40 e 100 \\
água pluvial (\%) & 0,8 \\
Coeficiente de escoamento superficial (runoff) & 2 \\
Descarte do escoamento inicial (mm) & 1987 a 2017 \\
Dados de precipitação diária &
\end{tabular}

Fonte: Autores (2018).

Tabela 4 - Volumes ideais dos reservatórios de água pluvial.

\begin{tabular}{ccc}
\hline $\begin{array}{c}\text { Percentual da } \\
\text { demanda total a ser } \\
\text { substituída por água } \\
\text { pluvial (\%) }\end{array}$ & $\begin{array}{c}\text { Volume do } \\
\text { reservatório } \\
\text { inferior }(L)\end{array}$ & $\begin{array}{c}\text { Potencial de economia de água } \\
(\%)\end{array}$ \\
\hline 40 & 19.250 & 23,21 \\
100 & 18.750 & 33,19 \\
\hline
\end{tabular}

Fonte: Autores (2018).

O potencial de atendimento da demanda do Bloco I depende do ajuste entre a captação de água de chuva (definida pela pluviometria, área de captação e coeficiente de escoamento) e a demanda a atender. Na simulação dos potenciais, foi possível comparar e analisar os percentuais de água para usos não potáveis a ser substituída e dessa forma indicar o volume ideal para o reservatório inferior a partir dos dados obtidos. A Figura 5 ilustra os resultados dos potenciais de economia de água para fins não potáveis, obtidos através das variações dos diferentes percentuais da demanda total a ser substituída por água pluvial e variações dos diferentes volumes de reservatórios.

Figura 5 - Potencial de economia de água para fins não potáveis em função da capacidade do tanque de água pluvial e da demanda de água da chuva de 40 e $100 \%$.

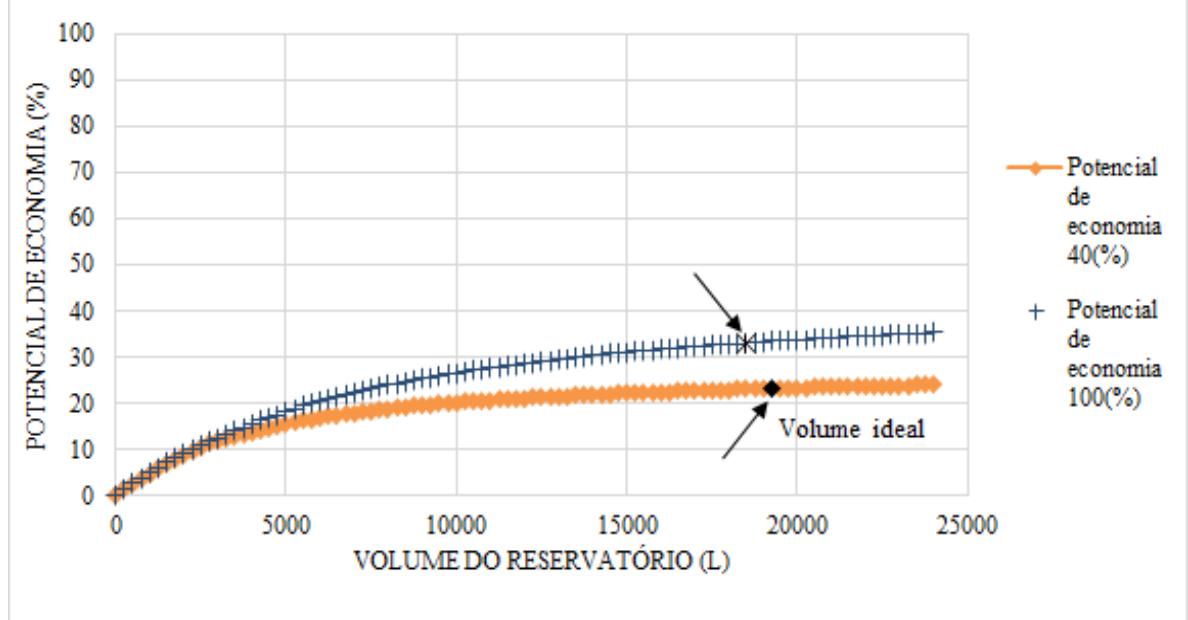

Fonte: Autores (2018). 
Entre as variáveis dos percentuais é possível observar que para 40\% de água para usos não potáveis a ser substituída por pluvial, estimou-se um reservatório de $19.250 \mathrm{~L}$ para um potencial econômico de água para fins não potáveis de 23,21\%, sendo assim 16,79\% a menos do que o previsto. O valor encontrado por Zhang et al., (2015) é similar ao encontrado no presente estudo, visto que estimaram um potencial de aproximadamente $23 \%$ para uso da água da chuva em edifícios altos em cidades australianas.

Ghisi, Thives e Paes (2018), avaliaram a possibilidade de utilização de água pluvial para fins não potáveis em um prédio público de Florianópolis e verificaram que o potencial de economia de água varia de $26,70 \%$ a $64,70 \%$, dependendo da demanda de água pluvial a ser utilizada. Os autores ainda consideraram o reservatório ideal aquele que atenderia a maior quantidade de dias por ano, isto é, aquele com maior atendimento completo.

Já para a simulação feita com 100\% de água para usos não potáveis a ser substituída por pluvial, foi estimado um reservatório de $18.750 \mathrm{~L}$, obtendo um potencial de economia de água para fins não potáveis de 33,19\%, resultando em $66,81 \%$ abaixo do previsto. Tal valor está de acordo aos estudos de Sousa, Silva \& Meireles (2018) realizados em prédios comerciais que mostram potenciais de $20 \%$ a $50 \%$ de economia de água não potável.

Definidos os volumes do reservatório de água, analisou-se ainda o comportamento da demanda de água pluvial atendida completamente (C), parcialmente (P) e não atendida (NA) para cada percentual, além do volume extravasado como demonstra a Tabela 5, a seguir.

Tabela 5 - Volume extravasado e percentuais de atendimento para demanda de 40 e $100 \%$.

\begin{tabular}{lccccc}
\hline $\begin{array}{c}\text { Percentual da } \\
\text { demanda total } \\
\text { a ser } \\
\text { substituída } \\
\text { por água } \\
\text { pluvial (\%) }\end{array}$ & $\begin{array}{c}\text { Potencial } \\
\text { de } \\
\text { economia } \\
\text { de água } \\
(\%)\end{array}$ & $\begin{array}{c}\text { Volume } \\
\text { extravasado } \\
\text { (L/dia) }\end{array}$ & $\begin{array}{c}\text { Demanda de } \\
\text { água pluvial } \\
\text { atendida } \\
\text { completamente } \\
(\%)\end{array}$ & $\begin{array}{c}\text { Demanda de } \\
\text { água pluvial } \\
\text { atendida } \\
\text { parcialmente } \\
(\%)\end{array}$ & $\begin{array}{c}\text { Demanda } \\
\text { de água } \\
\text { pluvial não } \\
\text { atendida } \\
(\%)\end{array}$ \\
\hline $\begin{array}{l}\text { Situação A - } \\
40\end{array}$ & 23,21 & $1.499,81$ & 55,75 & 4,88 & 39,37 \\
\hline $\begin{array}{l}\text { Situação B - } \\
100\end{array}$ & 33,19 & $1.012,32$ & 27,85 & 14,24 & 57,81 \\
\hline
\end{tabular}

Fonte: Autores (2018).

O volume extravasado de água pluvial no reservatório para a situação "A" teve uma média de 1.499,81 L/dia, determinado principalmente pelos dias dos meses em que há altos índices pluviométricos. Apesar do volume extravasado de água pluvial para reservatório da situação "B" ser menor que o da situação "A", ambas as situações apresentaram perda de água significativa devido à demanda por água de chuva do Bloco I ser baixa em relação ao volume de água captado na área do telhado, no qual é elevado, ocasionando em maiores perdas de água pluvial por escoamento.

Ademais, pôde-se perceber claramente na situação "B" a diminuição do volume extravasado quando se aumenta o percentual da demanda total a ser substituída por água pluvial para 100\%. Isso ocorre devido ao fato do volume de água pluvial a ser consumida durante os meses ser relativamente maior em relação à situação "A", que apresenta percentual de demanda total a ser substituída por água pluvial de $40 \%$.

Ainda em relação aos resultados apresentados na Tabela 5, nota-se que mediante o aumento do percentual da demanda total a ser substituída por água pluvial, o atendimento completo diminui respectivamente, fato que pode ser observado na coluna "Demanda de água pluvial atendida completamente".

Para determinação do volume ideal, analisou-se o intervalo de valores onde são considerados o volume máximo e o intervalo entre volumes, a diferença de percentual e a demanda atendida. Nesse sentido, o volume máximo determinado para as 
simulações foi de $24.000 \mathrm{~L}$, com intervalo de $250 \mathrm{~L}$, levando em consideração a abrangência da área disponível para implantação. Os resultados das simulações apresentaram volume inferior ao estimado, enquadrando-se nesse quesito.

Foi possível observar que, nos meses que correspondem ao período chuvoso na região são os que apresentam maior potencial de economia. No entanto, ao considerar a diferença dos percentuais, o potencial econômico de 33,19\% não alcançou um índice satisfatório, pois apresentou maior diferença em relação ao de entrada (100\%), apesar de superior e apresentar menor volume entre as simulações.

Assim, o volume ideal determinado para este caso é de 19.250 L, conforme observado na Tabela 4 que embora apresente maior volume para reservatório entre os simulados e menor potencial econômico, a diferença entre o índice de entrada (40\%) previsto é menor. Fonseca, Júnior e Faria (2017) ressaltam que apesar dos reservatórios maiores apresentarem custos mais altos há uma maior eficiência no sistema. Além disto, a diferença entre os resultados dos volumes do reservatório foi de $500 \mathrm{~L}$, não variando significativamente.

Para este volume ideal, o atendimento completo da demanda ocorre em 55,75\%, ou seja, cerca de 203 dias, dos dias simulados da série histórica analisada, com apenas 4,88\%, ou seja, 18 dias sem volume aproveitável de chuva suficiente para suprir a demanda de água pluvial; e 39,37\%, correspondendo a 144 dias com o reservatório vazio, ou seja, sem ocorrência de precipitação.

Em contrapartida, o reservatório com potencial de economia de 33,19\%, a demanda de água pluvial atendida completamente ocorre somente em 27,85\% dos dias, o que corresponde a 102 dias, atende parcialmente com 14,24\%, ou seja, 52 dias sem volume aproveitável de chuva suficiente para suprir a demanda por água pluvial; e 211 dias $(57,81 \%)$ sem atendimento. Isso ocorre devido ao fato de haver maior consumo de água da chuva nos meses com maiores níveis de precipitação, de forma que venha faltar água nos meses com pouca chuva.

Através da simulação no programa Netuno, pôde-se determinar um consumo médio de $1.182 \mathrm{~L} /$ dia de água pluvial, para o reservatório de 19. $250 \mathrm{~L}$, sendo a demanda de água para fins não potáveis do Bloco I de $2.628 \mathrm{~L} /$ dia para água pluvial (40\%), o que representa mais da metade da demanda por água para fins não potáveis suprida.

\subsection{Reservação}

O sistema de armazenamento de água pluvial do Bloco I será constituído de um reservatório inferior (1) com capacidade de $19.250 \mathrm{~L}$ e 12,96 $\mathrm{m}^{2}$ de área com dimensões de 3,6m x 3,6m e 1,5m de profundidade, situado próximo as calhas do telhado (2), conforme ilustrado na Figura 6. Essas calhas serão interligadas de forma aérea para fins de captação da água precipitada, com tubulação de recalque de 2,90m (3); e tubulação de $150 \mathrm{~mm}$ que permite a vazão com folga. 
Figura 6 - Sugestão de local para reservatório de água pluvial.

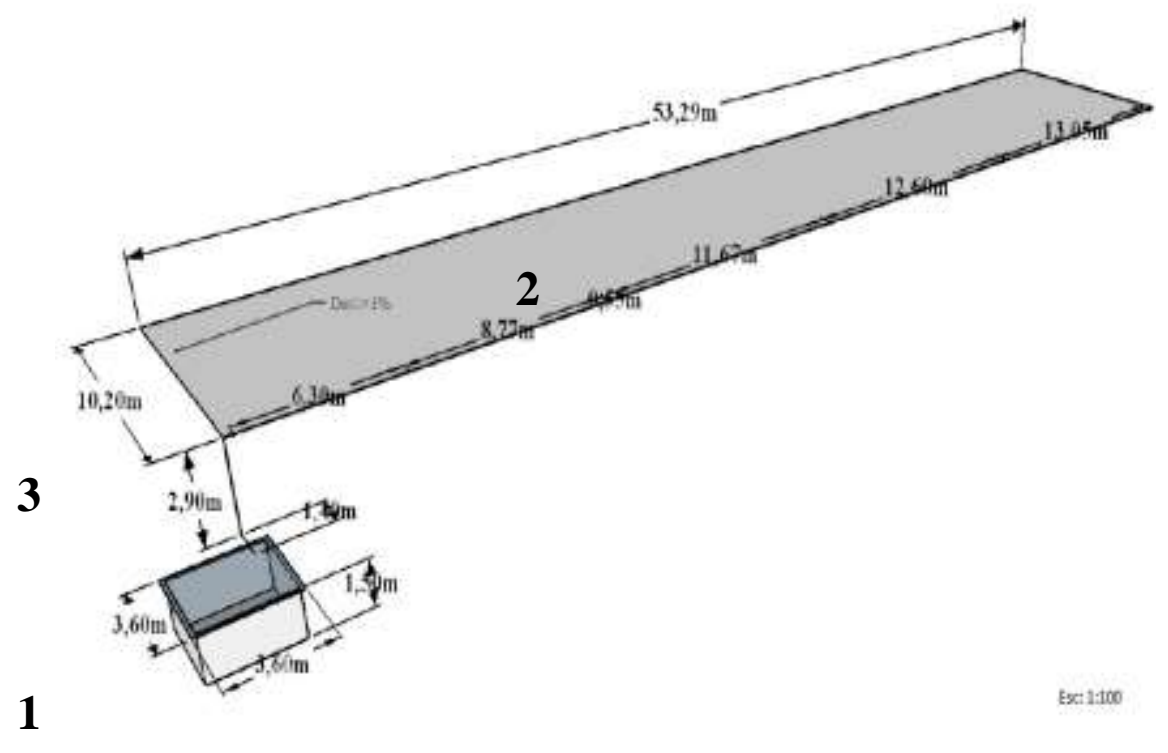

Fonte: Autores (2018).

O reservatório será munido de dispositivos como filtro, que permite a retenção de sólidos como folhas, galhos, papéis e outros resíduos maiores; bomba que possibilite o recalque da água aos pontos de consumo; tubulações de modo que proporcione o transporte e distribuição da água para área de interesse, entre outros.

\section{Conclusão}

Os resultados mostram que existe um ótimo índice pluviométrico em Marabá além de excelentes áreas de captação na universidade que, favorece o aproveitamento de água de chuva, contribuindo para o uso racional da água e a preservação dos recursos hídricos e de acordo com a simulação realizada no software Netuno 4.0. Estimou-se a reservação de um volume de 19.250 L para o reservatório, com percentual de substituição de água para fins não nobres de $40 \%$ e com potencial de economia de 23,21\%, atendendo mais da metade da demanda de água para fins não potáveis no Bloco I da UEPA. Entretanto, é necessária a realização de uma análise econômica, de ocupação do terreno e de consumo de energia elétrica a fim de se avaliar a viabilidade do projeto.

Além disto, é importante ressaltar que a escolha dos volumes dos reservatórios de águas pluviais no presente caso poderia ter sido diferente, de modo a priorizar os potenciais de economia, porém, a escolha das configurações mais adequadas ocorreu em função do atendimento da demanda por água de chuva. Os resultados mostrados foram baseados em dados passados, mas a chuva no futuro pode ter padrões diferentes e assim, o potencial de economia de água para usos não potáveis pode ser outros.

\section{Referências}

ABCMAC - Associação Brasileira de Captação e Manejo de água de chuva. http://www.abcmac.org.br/index.php.

Associação Brasileira de normas técnicas - ABNT. NBR 10844 (1989) - Instalações prediais de águas pluviais. R

Associação Brasileira de normas técnicas - ABNT. NBR 15527 - Água de chuva - Aproveitamento de coberturas em áreas urbanas para fins não potáveis (2007).

Adugna, D., Jensen, M. B., Lemma, B,, \& Gebrie, G. S (2018). Assessing the Potential for Rooftop Rainwater Harvesting from Large Public Institutions (2018). Rev. Int. J. Environ. Res. Public Health, 15, 336.

Agência nacional de águas - ANA. Sindicato da Indústria da Construção do Estado de São Paulo - SINDUSCON (2005). Conservação e reuso da água em edificações. São Paulo, 2005. http://www.fiesp.com.br/indices-pesquisas-e-publicacoes/conservacao-e-reuso-de-aguas-em-edificacoes-2005/. 
Alvares, C. A., Stape, J. L., Sentelhas, P. C., Gonçalves, J. L. M., \& Sparovek, G (2013). Köppen's climate classification map for Brazil (2013). Meteorologische Zeitschrift, 22, 711-728.

BRASIL. Lei n. 13.501/2017, de 30 de out. de 2017 (2017). Incentivo a captação e aproveitamento de águas pluviais.

BRASIL. Lei n. 9.433, de 8 de jan. de 1997 (1997). Política Nacional de Recursos Hídricos.

BRASIL. Lei n 10.725/03, de 18 de set. de 2003 (2003). Programa de conservação e uso racional da água em edificações- PURAE.

BRASIL. Lei $\mathrm{n}^{\circ}$ 13.276, de 05 de janeiro de 2002. Torna obrigatória a execução de reservatório para as águas coletadas por coberturas e pavimentos nos lotes, edificados ou não, que tenham área impermeabilizada superior a $500 \mathrm{~m}^{2}(2002)$.

Cohim, E., Garcia, A., \& Kiperstok, A. Captação e aproveitamento de água de chuva: dimensionamento de reservatórios (2008). Simpósio de Recursos Hídricos do Nordeste, 9 .

Eroksuz, E., \& Rahman, A (2011). Rainwater tanks in multi-unit buildings: A case study for three Australian cities (2010). Resources, Conservation and Recycling. https://www.sciencedirect.com/science/article/abs/pii/S0921344910001576.

Fewkes, A (1999). The use of rainwater for WC flushing: the field testing of a collection system. Building and Environment (1999), 34, 765-772.

Fonseca, T. D. S., Júnior, L. U. R., \& Faria, J. $\quad$ P. R (2017). Estudo da viabilidade econômica do aproveitamento de água de chuva para fins não potáveis em residências em Itajubá-Minas Gerais (2017). Revista Científica da FEPI-Revista Científica Universitas.

Galvíncio, J. D., \& Moura, M. S. B (2015). Aspectos climáticos da captação de água de chuva no Estado de Pernambuco (2015). Revista de Geografia. Recife: UFPE - DCG/NAPA, 22. https://www.alice.cnptia.embrapa.br/alice/bitstream/doc/157649/1/Magnacpatsa2.pdf.

Ghisi, E., \& Cordova, M. M (2014). Manual Netuno 4.0: aproveitamento de água pluvial. Programa computacional. Universidade Federal de Santa Catarina (2014). www.labeee.ufsc.br.

Ghisi, E., \& Ferreira, D. F (2017). Potential for potable water savings by using rainwater and greywater in a multi-storey residential building in southern Brazil (2017). Rev. Building and Environment, 42, 2512-2522. https://www.sciencedirect.com/science/article/abs/pii/S0360132306001971?via\%3Dihub.

Ghisi, E., Thives, L. P., \& Paes, R. F. W (2018). Investment feasibility analysis of rainwater harvesting in a building in Brazil (2018). Rev. Water Science \& Technology: Water Supply, 1497-1504.

Instituto Nacional de Meteorologia - INMET. Banco de Dados Meteorológicos para Ensino e Pesquisa (BDMEP). http://www.inmet.gov.br/portal.

Kalbusch, A., Gonçalves, F., Cureau, R. J., Defaveri, D., \& Ramos, D. A (2018). Avaliação das condições de operação de equipamentos hidrossanitários em edificações públicas (2018). Rev Ambiente Construído, 393-408.

Lima, J. A., Dambros, M. V. R., Antonio, M. A. P. M., Janzen, J. G., Marchetto, M (2011). Potencial da economia de água potável pelo uso de água pluvial: análise de 40 cidades da Amazônia (2011). Revista de Engenharia Sanitária e Ambiental, 16,

Lima, K. L. B.A., Nunes, L. G. C.F., \& Silva, S. R (2017). Análise da viabilidade de implantação de captação de águas pluviais em escola pública no RecifePE (2017). Revista Nacional de Gerenciamento de Cidades, 05,

Lopes, A. P. G., \& Miranda, D. A (2016). Análise Crítica De Métodos Para Dimensionamento De Reservatórios De Água Pluvial Estudo Comparativo Dos Municípios De Belo Horizonte (Mg), Recife (Pe) E Rio Branco (Ac) (2016). Revista Scientia Cum Industria (Sci. Cum Ind.), 87 —1.

Marinoski, D. L., Ghisi, E., \& Gómez, L. A (2004). Aproveitamento de Água Pluvial e Dimensionamento de Reservatório Para Fins Não Potáveis: estudo de caso em um conjunto residencial localizado em Florianópolis-SC (2004). Conferência Latino-Americana de Construção Sustentável. https://www.researchgate.net/publication/300006296_Aproveitamento_de_agua_pluvial_e_dimensionamento_de_reservatorio_para_fins_nao_potaveis_estudo _de_caso_em_um_conjunto_residencial_localizado_em_Florianopolis-SC/link/5a78954faca2722e4df30d26/download.

Morais, J. W. A (2017). Viabilidade Técnica/econômica no aproveitamento de água de chuva para fins não potáveis em uma instituição de ensino do Amazonas (2017). Dissertação de Mestrado em Engenharia de Produção pela Universidade Federal do Amazonas, Programa de Pós Graduação em Engenharia de Produção, Manaus.

Nascimento, T. V., Fernandes, L. L., \& Yoshino, G. H (2016). Potencial de Aproveitamento de Água de Chuva na Universidade Federal do Pará (2016). Revista Monografias Ambientais - REMOA, 105-116.

Pacheco, P. R. C, L. C. G. A view of the legislative scenario for rainwater harvesting in Brazil (2017). Rev. Journal of Cleaner Production, 290-294. https://www.sciencedirect.com/science/article/pii/S095965261631438X?casa_token=fCtMqvv4dp4AAAAA:47KfxLS2Hbg4K7GA_vQdv1HCotL4ptUnN6p AP8j1abWUZuKdBJTtQ5Cabq8TT4q6CF0DHVQ06km.

Rezende, J. H., \& Tecedor, N (2017). Aproveitamento de água de chuva de cobertura em edificações: dimensionamento do reservatório pelos métodos descritos na NBR 15527 (2017). Rev. Ambient. Água, 12,

Rupp, R. F., Munarim, U., \& Ghisi, E (2011). Comparação de métodos para dimensionamento de reservatórios de água pluvial (2011). Rev. Ambiente Construído. 47-64.

Salla, M. R., Lopes, G. B., Pereira, C. E., Neto, J. C. M., \& Pinheiro, A. M (2013). Viabilidade técnica de implantação de sistema de aproveitamento de água pluvial para fins não potáveis em universidade (2013). Rev. Ambiente Construído, 13. 
Sousa, V., Silva, C. M., \& Meireles, I. C. Technical-financial evaluation of rainwater harvesting systems in commercial buildings-case ase studies from Sonae Sierra in Portugal and Brazil (2018). Rev. Environmental Science and Pollution Research, 19283-19297.

Teixeira, C. A., Zattoni, G. T., Nagalli, A., Freira, F. B., \& Teixeira, S. H. C (2016). Análise de viabilidade técnica e econômica do uso de água de chuva em uma indústria metalmecânica na região metropolitana de Curitiba PR (2016). Revista Gest. Prod. São Carlos, 638-648.

Tomaz, P. A (2003). Economia de Água para Empresas e Residências - Um Estudo Atualizado sobre o Uso Racional da Água (2003). Navegar Editora, São Paulo. Recuperado em 12 abril de 2018, de http://iph.org.br/acervo/livros/economia-de-agua-para-empresas-e-residencias-um-estudo-atualizado-sobre-o-usoracional-da-agua-591.

Tomaz, P (2009). Qualidade da água de chuva. Aproveitamento de água de chuva (2009). http://pliniotomaz.com.br/livros-digitais/.

Torquato, A. S., Moreira, A., \& Bittencourt, P.R.S (2015). Captação E Utilização De águas Pluviais Para Fins não-Potáveis (2015). Revista Uningá Review, 47-54.https://labeee.ufsc.br/sites/default/files/publicacoes/tccs/TCC_Ana_Kelly_Marinoski.pdf.

Tugoz, J. E., Bertolini, G. R. F., \& Brandalise, L.T (2017). Captação E Aproveitamento Da Água Das Chuvas: O Caminho Para Uma Escola Sustentável (2017). Rev. De Gestão Ambiental e Sustentabilidade -GeAS. http://www.revistageas.org.br/ojs/index.php/geas/article/view/396.

Vialle, C., Sablayrolles, C., Lovera, M., \& Huau, M. C (2011). Montréjaud-vignoles, M. Modelling of a roof runoff harvesting system: The use of rainwater for toilet flushing (2011). Rev. Water Science and Technology: Water https://www.researchgate.net/publication/269599369_Modelling_of_a_roof_runoff_harvesting_system_The_use_of_rainwater_for_toilet_flushing/link/55813f bf08ae47061e5f4ce5/download.

Villarreal, E., \& Dixon, A (2005). Analysis of a rainwater collection system for domestic water supply in Ringdansen, Norrköping, Sweden (2005). Building and Environment, 1174-1184. https://www.sciencedirect.com/science/article/abs/pii/S0360132304003178.

Von Sperling, M (2014). Princípios do tratamento biológico de águas residuárias: Introdução à qualidade das águas e ao tratamento de esgotos (2014). (4a ed.), Editora UFMG, http://www.smarh.eng.ufmg.br/defesas/190M.PDF.

Yoshino, G. H., Fernandes, L. L., Ishihara, J. H, \& Silva, A. I. M (2014). Use of Rainwater for non-potable purposes in the Amazon (2014). Rev. Environmental, Development and Sustainability, 431-442. https://link.springer.com/article/10.1007/s10668-013-9485-6.

Yoshino, G. H (2012). O aproveitamento de água de chuva para fins não potáveis na cidade universitária professor José da Silveira Netto-Belém/PA (2012). Dissertação de Mestrado em Engenharia Civil pela Universidade Federal do Pará, Programa de Pós-Graduação em Engenharia Civil, Belém-PA.

Zhang, Y., Chen, D., Chen, L., \& Ashbolt, S (2015). Potential for rainwater use in high-rise buildings in Australian cities (2015). Journal of Environmental Management, 222-226. https://www.sciencedirect.com/science/article/pii/S0301479709002849.

Zhou, Y., Shao, W., \& Zhang, T (2010). Analysis of a Rainwater Harvesting System For Domestic Water Supply in Zhoushan, China (2010). Journal of Zhejiang University SCIENCE A $\quad$ Applied $\quad$ Physics Engineering, https://www.researchgate.net/publication/225763271_Analysis_of_a_Rainwater_Harvesting_System_for_Domestic_Water_Supply_in_Zhoushan_China. 